\title{
MAPPING SURFACE FLOW VELOCITIES OF SIACHEN AND GANGOTRI GLACIERS USING TERRASAR-X AND SENTINEL-1A DATA BY INTENSITY TRACKING
}

\author{
Preet Lal ${ }^{1,}$, Divya Sekhar Vaka², Y. S. Rao ${ }^{2}$ \\ ${ }^{1}$ Centre for Land Resource Management, Central University of Jharkhand, India. - preet.lal@cuj.ac.in \\ ${ }^{2}$ Centre of Studies in Resources Engineering, Indian Institute of Technology Bombay, India. - sekharv@iitb.ac.in, \\ ysrao@csre.iitb.ac.in
}

\section{Commission V, SS: Atmosphere, Ocean, Weather and Climate}

KEY WORDS: Glacier velocity, offset tracking, Karakoram Range, Garhwal Himalayas

\begin{abstract}
:
Glaciers are melting at an alarming rate due to global warming. Two major glaciers of India viz. Gangotri and the Siachen are chosen for the velocity mapping. The line-of-sight (LOS) velocity fields are derived using X-band TerraSAR-X and C-band Sentinel-1A datasets. An intensity-based offset tracking method is used to generate LOS velocities of the glaciers. The single look complex (SLC) images of the TerraSAR-X are converted into intensity before applying the offset tracking method, whereas the ground range detected (GRD) products from Sentinel-1A are directly used to estimate the glacier velocities. The Siachen glacier velocity is mapped using three X-band images from 2011 to 2017 and a C-band image between 2017 and 2018. The X-band images in the case of Siachen are available with the long-time interval between the master and slave images. The velocity of the glacier is observed to be around $30-40$ $\mathrm{cm} \mathrm{day}^{-1}$ from X-band and around 45-50 $\mathrm{cm}_{\text {day }}{ }^{-1}$ from C-band. Three X-band images in the year 2012 and a C-band image in the year 2018 are used for the Gangotri glacier velocity estimation. These images are very closely separated in time, and the velocity of the glacier is found to be $15-20 \mathrm{~cm}_{\text {day }}{ }^{-1}$. A dataset with a temporal gap of approximately three years is also used for the Gangotri glacier velocity estimation and observed a large difference in velocity $\left(\sim 10 \mathrm{~cm} \mathrm{day}^{-1}\right)$ from that of shorter interval data. Therefore, for a slowmoving glacier like Gangotri, a dataset with a high temporal gap may not give a reliable result. It is also observed that X-band TerraSAR-X results are more accurate than the C-band Sentinel-1A results. The penetration depth of X-band is less compared to Cband, which might result in accurate estimation of glacier surface flow. According to the results, the velocity of the Siachen glacier is increasing at a very high rate.
\end{abstract}

\section{INTRODUCTION}

Glacier velocity mapping is a very growing research interest now a day due to the climate change. A very little is known about the Indian Himalayan glacier because of the inaccessibility of the filed data or the field survey. Glaciers are made of snow that gets deposited over many years, compresses and made into large thickened ice masses. The Himalayan glaciers are very sensitive to climate change and lead to the increase in temperature and retardation of some degree of precipitation (Liu et al. 2006; Mayewski and Jeschke 1979; McCarthy et al. 2001). Due to downwasting of the glacier in the recent decades, numerous supraglacial lakes have been formed and also undergone expansion (Benn, Wiseman, and Hands 2001). The glacial velocity is a very important study to understand glacier flow properties and mass balance (Gray et al. 2001).

Remote sensing is a very useful technique for studying glacial changes and glacial dynamics. The optical and the microwave remote sensing data are widely used for estimating glacier velocity. Because of the variability in the weather and due to the higher elevation of the glacial region, it is challenging to get the cloud-free optical image pairs. The presence of cloud cover reduces the image quality and thus making the data less suitable for velocity estimation. On the other hand, Synthetic Aperture Radar (SAR) is all weather, day and night capable, acquiring data from different look angles. The SAR signals can penetrate through the cloud with very less signal attenuation, thus making it more capable for glacier velocity estimation. In optical remote sensing, feature tracking approach is used for the glacier velocity estimation (Copland et al. 2009; Joughin et al. 2010), whereas by using SAR datasets two-dimensional glacier velocity can be estimated using Differential Synthetic Aperture Radar Interferometry (DInSAR) technique and intensity tracking technique (Pritchard et al. 2005; Strozzi et al. 2002).

Using the feature tracking approach, various studies of Himalayan glacial ice motion are reported using different optical satellite data like ASTER, SPOT-5, Landsat-TM (Copland et al. 2009; Leprince et al. 2008; Scambos et al. 1992; Schellenberger et al. 2015; Scherler, Leprince, and Strecker 2008). The results from these studies are limited to some part of glacier due to the presence of cloud cover or shadow in the optical data.

The Siachen and Gangotri glacier velocities are studied using ERS-1/2 SAR tandem data of April 1\& 21996 and March 25\&26 1996 respectively. Using the DInSAR technique, the velocity of the Siachen glacier is observed to be $22.4 \mathrm{~cm} \mathrm{day}^{-1}$, whereas the Gangotri glacier velocity is $8.4 \mathrm{~cm} \mathrm{day}^{-1}$ (Kumar, Venkataraman, and Rao 2009). Using the Stokes vector correlation approach the velocity of the Gangotri glacier between September and October 2012 was estimated to be around $18 \mathrm{~cm}$ day $^{-1}$ in the upper part of the glacier and around $8-10 \mathrm{~cm} \mathrm{day}^{-1}$ in the lower part of the glacier (Muhuri et al. 2015). A correlation between glacier movement and local topography is observed in a study aimed at estimating three-dimensional velocity of glaciers in Karakoram Range of Himalayas using ERS-1/2 tandem ascending and descending pass data (Kumar, Venkataramana, and Høgda

\footnotetext{
* Corresponding author
} 
2011). As the interferometric approach is limited by the temporal and geometric decorrelation, intensity tracking approach is more suitable for glacier velocity estimation. Intensity tracking is more useful when the duration between two SAR image acquisitions is more than 24 days.

\section{STUDY AREA AND DATASETS}

\subsection{Study Area}

Two glaciers (Gangotri and Siachen) located in a north-western part of Indian Himalayas are chosen glacier velocity mapping. The Gangotri is the most important glaciers in the Indian Himalayan region, which is said to be the source of the Ganga River. It is located in Uttarkashi district of Uttarakhand. It flows in a north-western direction making a ' $U$ ' shaped valley. A location map of the glacier is shown in Figure 1.

The Siachen glacier is located in Karakoram Range in the Himalayan region at an altitude of $5700 \mathrm{~m}$ from mean sea level to $3620 \mathrm{~m}$ at Indira Col. It is the second largest glacier after the polar region. The Nubra River originates from the glacier flows parallel to the Karakoram Range and then enters into the Tibet region. The location of the Siachen glacier is shown in Figure 2.

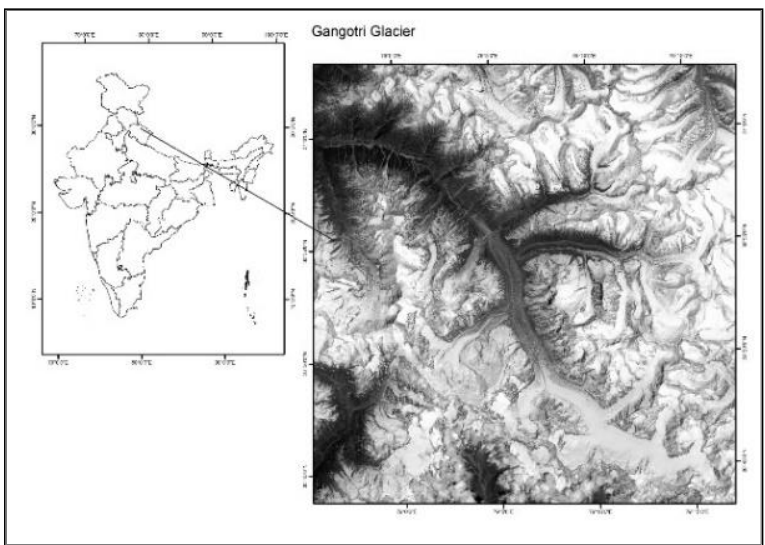

Figure 1: Gangotri glacier location map.

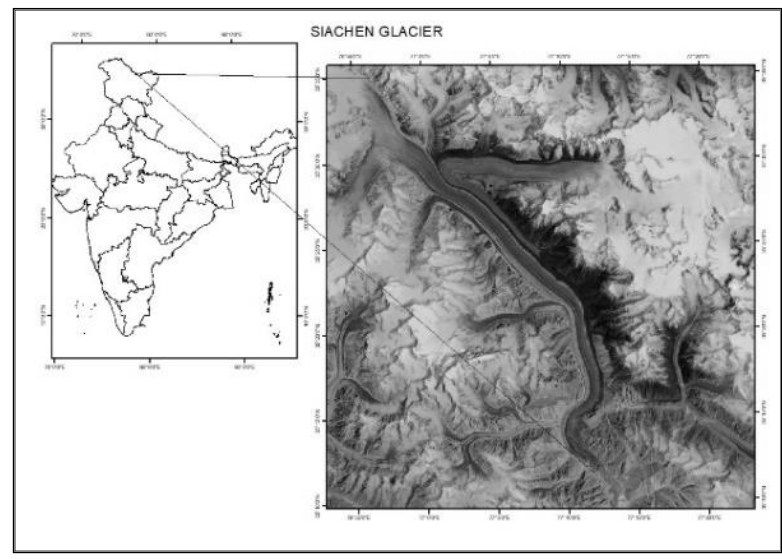

Figure 2: Siachen glacier location map.

\subsection{Data Used}

In this study, X-band TerraSAR-X and C-band Sentinel-1A data pairs are used for glacier velocity estimation. TerraSAR-X launched by the German Aerospace Center (DLR) operates in different modes - Spotlight, Stripmap, and ScanSAR. The higher resolution supports the identification and separation of single scatterers. Imaging from this SAR sensor is possible in single, dual and quad-polarisation (Anon 2004). The revisit time of the satellite is seven days.

The Ground Range Detected (GRD) products from the European Space Agency's (ESA) Sentinel-1A satellite are used in this study. The data are made accessible to the users through the Copernicus Open Access Hub. The revisit time of the satellite is 12 days. The data pairs, which are used in the Siachen and Gangotri glacier velocity mapping are shown in Table 1.

Table 1: List of TerraSAR-X \& Sentinel-1A data pairs.

\begin{tabular}{|c|c|c|c|c|}
\hline Glacier & Satellite & $\begin{array}{c}\text { Date of } \\
\text { Acquisition }\end{array}$ & Pass & $\theta_{i n c}$ \\
\hline \multirow{7}{*}{$\begin{array}{l}\frac{D}{d} \\
\frac{\pi}{0} \\
\frac{\pi}{2}\end{array}$} & \multirow{5}{*}{$\begin{array}{l}\text { TerraSAR }-X \\
\text { (Strip Mode) }\end{array}$} & 19/09/2011 & \multirow{2}{*}{ Asc. } & $40.07^{\circ}$ \\
\hline & & 29/01/2012 & & $39.98^{\circ}$ \\
\hline & & $22 / 08 / 2013$ & \multirow{3}{*}{ Dsc. } & $43.86^{\circ}$ \\
\hline & & $03 / 02 / 2014$ & & $44.56^{\circ}$ \\
\hline & & $18 / 02 / 2017$ & & $43.86^{\circ}$ \\
\hline & \multirow{2}{*}{ Sentinel 1-A } & $26 / 05 / 2018$ & \multirow{2}{*}{ Asc. } & $31.37^{\circ}$ \\
\hline & & 05/06/2018 & & $31.89^{\circ}$ \\
\hline \multirow{5}{*}{ 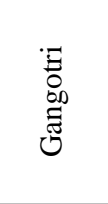 } & \multirow{3}{*}{$\begin{array}{l}\text { TerraSAR- X } \\
\text { (Strip Mode) }\end{array}$} & 03/06/2012 & \multirow{3}{*}{ Dsc. } & $38.39^{\circ}$ \\
\hline & & 25/06/2012 & & $38.39^{\circ}$ \\
\hline & & 06/07/2012 & & $38.39^{\circ}$ \\
\hline & \multirow{2}{*}{ Sentinel 1-A } & $10 / 05 / 2018$ & \multirow{2}{*}{ Dsc. } & $31.33^{\circ}$ \\
\hline & & $22 / 05 / 2018$ & & $31.98^{\circ}$ \\
\hline
\end{tabular}

Asc. - Ascending pass; Dsc. - Descending pass.

\section{METHODOLOGY}

Offset tracking methods estimate movement of the glacier between two images (master and slave) in both range and azimuth directions. These methods avoid one of the most critical steps (phase unwrapping) of interferometric processing. Offset tracking methods are adopted as an efficient alternative to the interferometric methods due to the decorrelation problem in interferometric approaches.

Using the ESA-SNAP software, the TerraSAR-X single-lookcomplex (SLC) images are converted into GRD products. A $2 \times 2$ multi-look is applied to the SLC images during the conversion process. After conversion, the TerraSAR-X GRD products have a spatial resolution of $4.3 \mathrm{~m}$. The Sentinel-1A data are directly available in GRD format with a pixel spacing of $10 \mathrm{~m}$. Orbital corrections are applied for the datasets before offset tracking. Window sizes of $256 * 64$ are selected for the estimation of glacial motion. The final results are terrain corrected, and then the velocity maps are generated.

\section{RESULTS AND DISCUSSIONS}

\subsection{Siachen Glacier}

The Siachen glacier velocity mapping is computed from TerraSAR-X and Sentinel-1A datasets from both ascending and descending pass images. During 19 Sept. 2011 to 29 Jan. 2012, the velocity of the Siachen glacier in ascending pass is around 30 $\mathrm{cm} \mathrm{day}^{-1}$ in ascending pass as shown in Figure 3. As the time of the estimation is in the winter, the velocity is observed to be moderate in the entire glacier region. 


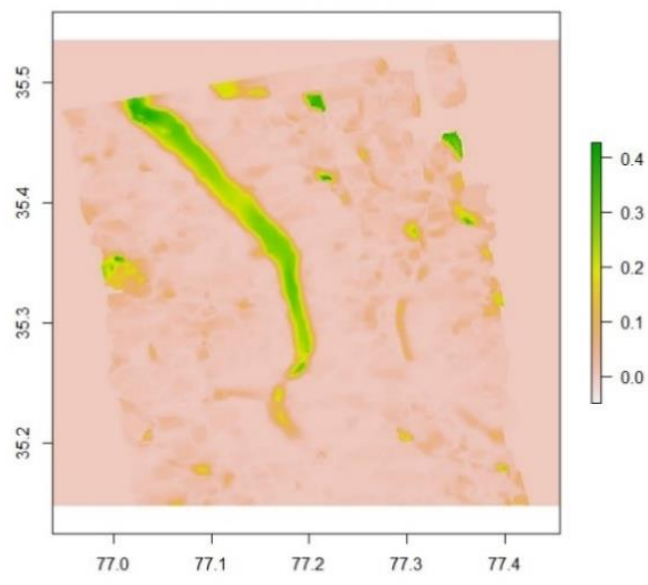

Figure 3: Siachen glacier velocity map using ascending pass TerraSAR-X images (19 Sept. 2011 and 29 Jan. 2012) (Figure scale in $\mathrm{m} \mathrm{day}^{-1}$ ).

Between, 22 Aug. 2013 and 03 Feb. 2014, using the descending pass images, the velocity of the Siachen glacier is observed to be around $35 \mathrm{~cm}$ day- 1 as shown in Figure 4 . There is a velocity increase of $5 \mathrm{~cm}$ day-1 from the year 2012

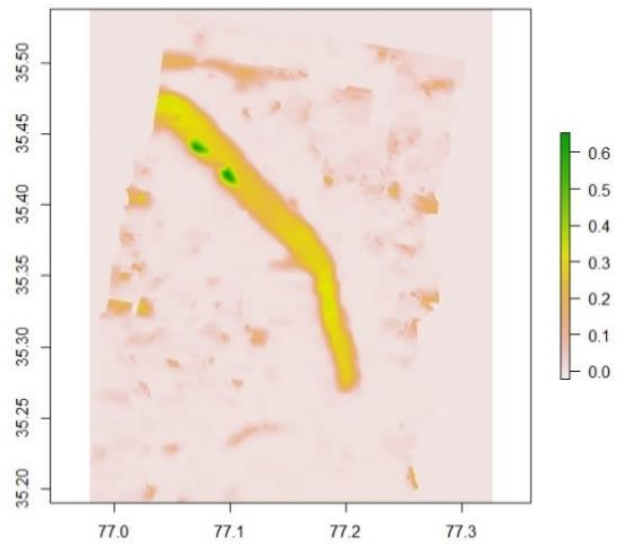

Figure 4: Siachen glacier velocity map using descending pass TerraSAR-X images. (22 Aug. 2013 and 03 Feb. 2014) (Figure scale in $\mathrm{m} \mathrm{day}^{-1}$ ).

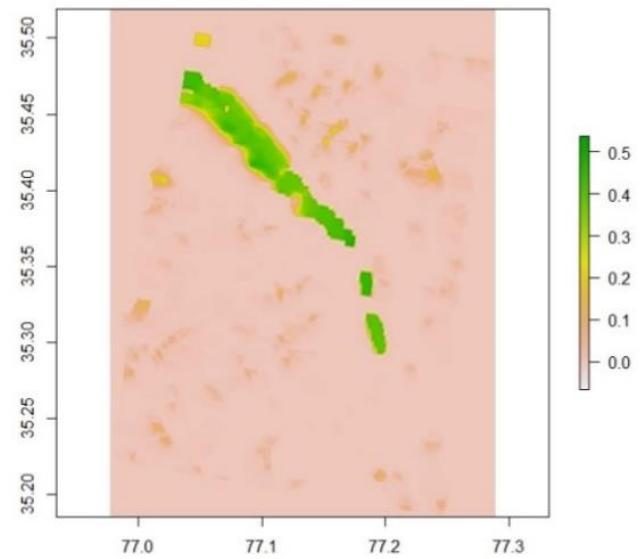

Figure 5: Siachen glacier velocity map using the descending pass TerraSAR-X images (03 Feb. 2014 and 18 Feb. 2017) (Figure scale in $\mathrm{m} \mathrm{day}^{-1}$ ).

The velocity of Siachen glacier estimated from TerraSAR-X descending pass images is around $42 \mathrm{~cm}^{\text {day }}{ }^{-1}$ between the years
2014-2017 as shown in Figure 5. There is a velocity increase of $5-7 \mathrm{~cm}$ day $^{-1}$ from the year 2013. The velocity is uniform across the glacier. From the result, it is observed that the Siachen glacier is retreating at a rate of $146 \mathrm{~m}_{\text {year }}^{-1}-153.3 \mathrm{~m}^{\text {year }}{ }^{-1}$ between years 2014 and 2017.

Using Sentinel-1A ascending pass images between May and June 2018, the Siachen glacier velocity is observed to be around $50-52 \mathrm{~cm} \mathrm{day}^{-1}$ as shown in Figure 6. The velocity is uniform across the glacier from the upper part to the lower part.

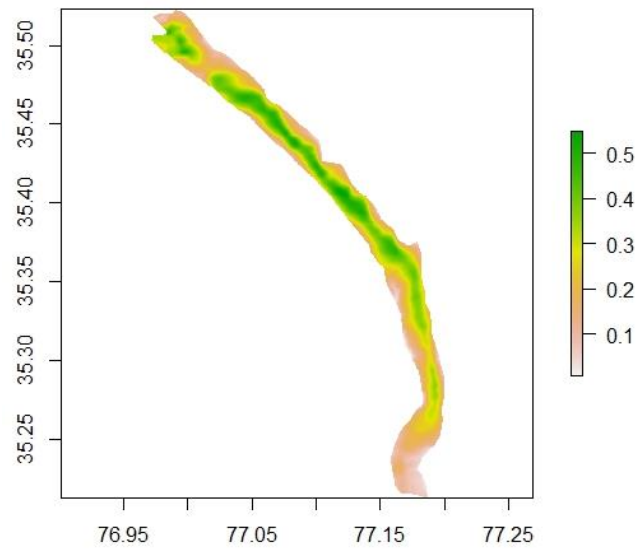

Figure 6: Siachen glacier velocity map using descending pass Sentinel-1A images (26 May 2018 and 7 June 2018) (Figure scale in $\mathrm{m} \mathrm{day}^{-1}$ ).

Ascending pass datasets of TerraSAR-X and Sentinel-1A are used of Siachen Glacier velocity estimation. Between Sept. 2011 and Jan. 2012, the velocity of the glacier is around $30 \mathrm{~cm}_{\text {day }}{ }^{-1}$, whereas between 26 May and 5 June 2018 the velocity is around $50 \mathrm{~cm}^{-1}{ }^{-1}$. It is observed that the velocity is increased by 15 $\mathrm{cm} \mathrm{day}^{-1}$ from 2012 to 2017 . There could be various reasons for this drastic increase in glacier velocity.

i) A change in wavelength of the datasets may affect the glacier velocity estimation due to different penetration capabilities.

ii) The TerraSAR- $X$ data are acquired in the winter season, whereas the Sentinel-1A data are acquired in the summer season. A change in velocity is expected in different seasons. Due to the melting of the glacier in the summer season, the velocity estimates are high.

For descending pass datasets, the velocity of the glacier between 2013 and 2014 is around 30-35 cm day ${ }^{-1}$, whereas between 2014 and 2017, the velocity of the glacier is around 40-45 $\mathrm{cm} \mathrm{day}^{-1}$. Thus within three years of gap, there is an increase of $10 \mathrm{~cm}^{-1} \mathrm{day}^{-}$ ${ }^{1}$ in the glacier velocity. The observations show that the Siachen glacier is melting at an alarming rate as compared to any other glacier like Samudra Tapu, whose velocity is around 7-10 cm day $^{-1}$ (Sood, Stein, and Thakur 2014). Earlier studies (in 1996) also show a high velocity of $22.4 \mathrm{~cm} \mathrm{day}^{-1}$ for the Siachen glacier (Kumar et al. 2009).

\subsection{Gangotri Glacier}

The Gangotri glacier velocity is computed from TerraSAR-X and Sentinel-1A datasets in descending pass. The glacier velocity between 3 June 2012 and 25 June 2012 is around 13-15 $\mathrm{cm} \mathrm{day}^{-1}$ in the upper part of the glacier, and the velocity is estimated to be around $10 \mathrm{~cm} \mathrm{day}^{-1}$ in the lower part of the glacier as shown in Figure 7. 


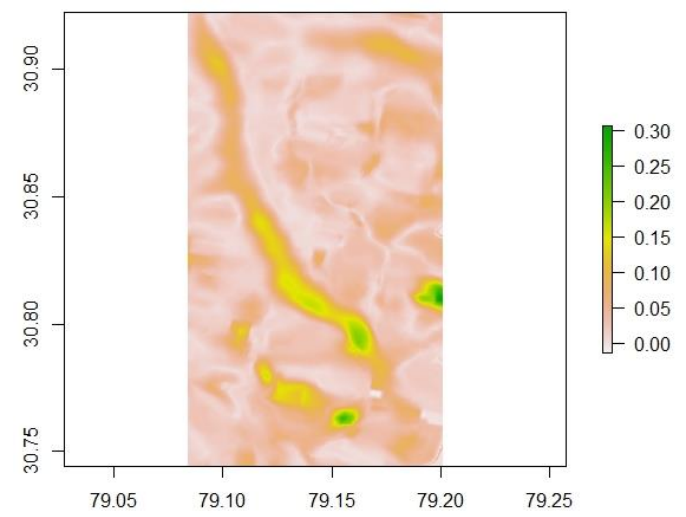

Figure 7: Gangotri glacier velocity map using descending pass TerraSAR-X images (03 June 2012 and 25 June 2012) (Figure scale in $\left.\mathrm{m} \mathrm{day}^{-1}\right)$.

The Gangotri glacier velocity between 25 June 2012 and 6 July 2012 was around $15-18 \mathrm{~cm}_{\text {day }^{-1}}$ in the upper and lower part of the glacier as shown in Figure 8. The velocity is almost the same as the previous estimation.

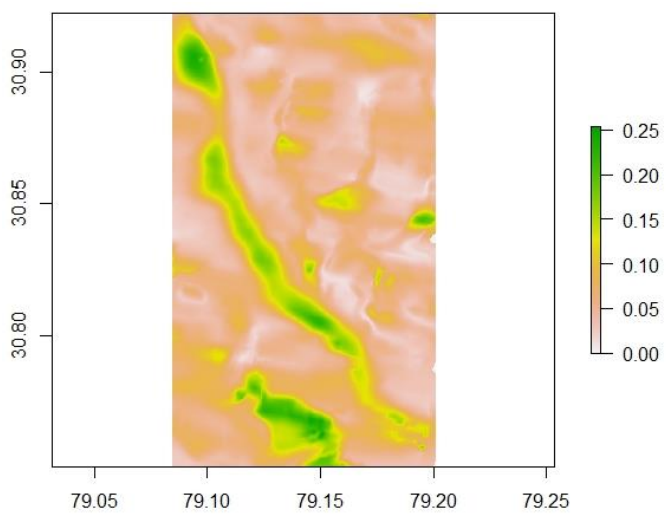

Figure 8: Gangotri glacier velocity map using descending pass TerraSAR-X images (25 June 2012 and 6 July 2012) (Figure scale in $\mathrm{m} \mathrm{day}^{-1}$ ).

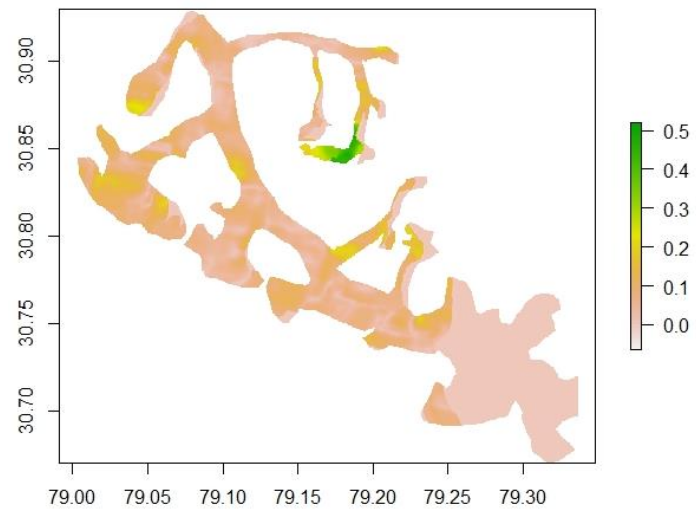

Figure 9: Gangotri glacier velocity map obtained descending pass Sentinel-1A images (10 May 2018 and 22 May 2018)

(Figure scale in $\mathrm{m} \mathrm{day}^{-1}$ ).

Using Sentinel-1A datasets, the Gangotri glacier velocity between 10 May 2018 and 22 May 2018 is estimated to be around $15-20 \mathrm{~cm}^{2} \mathrm{day}^{-1}$ as shown in Figure 9.
The results indicate moderate velocities for the Gangotri glacier. Between 3 June and 25 June 2012, the velocity is around 13-15 $\mathrm{cm}$ day $^{-1}$ and between 25 June and 6 July 2012, the velocity is around $15-18 \mathrm{~cm}$ day $^{-1}$. The glacier movement rate for the two consecutive months in the year 2012 is observed to be similar. In the year 2018, using Sentinel-1A data, the velocity of the glacier is estimated to be around $15-20 \mathrm{~cm} \mathrm{day}^{-1}$. In 1996 , the velocity of the Gangotri glacier was around $8 \mathrm{~cm} \mathrm{day}^{-1}$ (calculated using the interferometry processing of ERS-1/2 tandem data) (Kumar et al. 2009). After analyzing the results, it is observed that there is very less change in the velocity of the Gangotri glacier in the last six years.

\section{CONCLUSIONS}

The Siachen and Gangotri velocity maps demonstrate the use of SAR datasets for glacier velocity estimation. Though the intensity tracking results slightly deviate from interferometric results (Varugu, Singh, and Rao 2015), the technique is very useful for high temporal gap datasets. Particularly, intensity tracking is useful in the case of less coherence between image pairs.

The velocity of the Siachen glacier is found to be increasing at an alarming rate. Analyzing the results from this study, it is observed that the velocity of the glacier is around $30 \mathrm{~cm} \mathrm{day}^{-1}$ in the year 2012, which has increased to nearly $50 \mathrm{~cm} \mathrm{day}^{-1}$ in the year 2018. The velocity of the Gangotri glacier is found to be consistent from 2012 to 2018 . The velocity of the glacier is between $15-20 \mathrm{~cm} \mathrm{day}^{-1}$.

In general, for fast moving glaciers, intensity tracking technique is very useful as in most of the cases there is a chance of decorrelation due to changes in the surface features and atmospheric parameters. However, for slow-moving glaciers, the technique may produce a bias. The interferometric analysis is suitable slow-moving glaciers if the coherence is preserved between two images used for velocity estimation.

The present study is an attempt to estimate present velocities of Siachen and Gangotri glaciers using SAR data and intensity tracking approach. As a future study, these results are to be validated using ground truth data.

\section{ACKNOWLEDGMENTS}

Sentinel-1 data are provided free of cost by European Space Agency (ESA) through the Copernicus Open Access Hub. TerraSAR-X data is obtained from the German Aerospace Centre (DLR) through project code CALVAL-6884.

\section{REFERENCES}

Anon. 2004. "TerraSAR-X Science Plan TerraSAR-X."

Benn, D. I., S. Wiseman, and K. A. Hands. 2001. "Growth and Drainage of Supraglacial Lakes on Debris-Mantled Ngozumpa Glacier, Khumbu Himal, Nepal." Journal of Glaciology 47(159):626-38.

Copland, Luke et al. 2009. "Glacier Velocities across the Central Karakoram.” Annals of Glaciology 50(52):41-49.

Gray, A. L., N. Short, K. E. Mattar, and K. C. Jezek. 2001. "Velocities and Flux of the Filchner Ice Shelf and Its Tributaries Determined from Speckle Tracking Interferometry." Canadian 
Journal of Remote Sensing 27(3):193-206.

Joughin, Ian, Ben E. Smith, Ian M. Howat, Ted Scambos, and Twila Moon. 2010. "Greenland Flow Variability from Ice-SheetWide Velocity Mapping.” Journal of Glaciology 56(197):41530.

Kumar, V., G. Venkataramana, and K. A. Høgda. 2011. "Glacier Surface Velocity Estimation Using SAR Interferometry Technique Applying Ascending and Descending Passes in Himalayas." International Journal of Applied Earth Observation and Geoinformation 13(4):545-51.

Kumar, Vijay, G. Venkataraman, and Y. S. Rao. 2009. "Sar Interferometry and Speckle Tracking Approach for Glacier Velocity Estimation Using Ers-1 / 2 and Terrasar-X Spotlight High Resolution Data.” Engineering 332-35.

Leprince, Sébastien, Etienne Berthier, François Ayoub, Christophe Delacourt, and Jean Philippe Avouac. 2008. "Monitoring Earth Surface Dynamics With Optical Imagery." Eos, Transactions American Geophysical Union 89(1):1.

Liu, S. Y., Y. J. Ding, J. Li, D. H. Shangguan, and Y. Zhang. 2006. "Glaciers in Response to Recent Climate Warming in Western China." Quaternary Sciences 26(5):762-71.

Mayewski, Paul A. and Peter A. Jeschke. 1979. "Himalayan and Trans-Himalayan Glacier Fluctuations since AD 1812.” Arctic and Alpine Research 11(3):267-87.

McCarthy, James J., Osvaldo F. Canziani, Neil A. Leary, David J. Dokken, and Kasey S. White. 2001. "Contribution of Working Group II to the Third Assessment Report of the Intergovernmental Panel on Climate Change (IPCC)."

Contribution of Working Group II to the Third Assessment Report of the Intergovernmental Panel on Climate Change (IPCC) Cambridge University Press, London, UK P 1000.

Muhuri, Arnab, Avik Bhattacharya, Ryo Natsuaki, and Akira Hirose. 2015. "Glacier Surface Velocity Estimation Using Stokes Vector Correlation." Proceedings of the 2015 IEEE 5th Asia-Pacific Conference on Synthetic Aperture Radar, APSAR 2015 606-9.

Pritchard, Hamish, Tavi Murray, Adrian Luckman, Tazio Strozzi, and Stuart Barr. 2005. "Glacier Surge Dynamics of Sortebr??, East Greenland, from Synthetic Aperture Radar Feature Tracking." Journal of Geophysical Research: Earth Surface 110(3):1-13.

Scambos, Ted A., M. J. Dutkiewicz, J. C. Wilson, and R. A. Bindschadler. 1992. "Application of Image Cross-Correlation to the Measurement of Glacier Velocity Using Satellite Image Data." Remote Sensing of the Environment 42(September 1991):177-86.

Schellenberger, T., T. Dunse, A. Kääb, J. Kohler, and C. H. Reijmer. 2015. "Surface Speed and Frontal Ablation of Kronebreen and Kongsbreen, NW Svalbard, from SAR Offset Tracking." Cryosphere 9(6):2339-55.

Scherler, Dirk, Sébastien Leprince, and Manfred R. Strecker. 2008. "Glacier-Surface Velocities in Alpine Terrain from Optical Satellite Imagery-Accuracy Improvement and Quality Assessment." Remote Sensing of Environment 112(10):3806-19.
Sood, Sahil, Ir A. Stein, and Praveen Thakur. 2014. "Glacier Classification and Movement Estimation Using SAR Polarimetric and Interferometric Techniques, M.Sc. Dissertation, IIRS, Dehradun, UK, India.” 1-82.

Strozzi, Tazio, Adrian Luckman, Tavi Murray, Urs Wegmüller, and Charles L. Werner. 2002. "Glacier Motion Estimation Using SAR Offset-Tracking Procedures - White Rose Research Online." IEEE Transactions on Geoscience and Remote Sensing 40(11):2384-91.

Varugu, B. K., M. Singh, and Y. S. Rao. 2015. "Glacier Velocity Estimation Using High Resolution SAR Images - Application to Gangotri Glacier in Himalayas Glacier Velocity Estimation Using High Resolution SAR Images - Application to Gangotri Glacier in Himalayas." Proceedings (CD) of National Symposium on Geomatics for Digital India-Annual Conventions of Indian Society of Remote Sensing and Indian Society of Geomatics (ISRS-ISG) (January 2015). 